\title{
Prevalence of Sensitization to Food and Inhalant Allergens in Patients with Atopic Dermatitis in Gorgan, North of Iran
}

\author{
Mohammad Sobhani Shahmirzadi ${ }^{1}$, Jabbar Parhiz ${ }^{1}$, Bagher Pahlavanzade², Masoud Mohammadi ${ }^{3,4}$, \\ Mohsen Ebraimi*1 \\ 1. Neonatal and Children's Health Research Center, Golestan University of Medical Sciences, Gorgan, \\ Iran \\ 2. Department of Biostatistics, School of Allied Medical Sciences, Shahid Beheshti University of \\ Medical Sciences, Tehran, Iran \\ 3. Golestan Research Center of Gastroenterology and Hepatology, Golestan University of Medical \\ Sciences, Gorgan, Iran \\ 4. Department of Medical Library \& Information Sciences, Faculty of Allied Medical Sciences, Tehran \\ University of Medical Sciences, Tehran, Iran.
}

\section{ABSTRACT}

Background and objectives: Atopic dermatitis is a chronic inflammatory allergic disease that specifically affects the skin. The incidence of this disease is influenced by genetic and physical stimuli, hormones, stress and food and inhalant allergens. Given the increasing prevalence of atopic dermatitis, it is important to identify food and inhalant allergens associated with the disease. The purpose of this study was to evaluate prevalence of sensitization to food and inhalant allergens in children with atopic dermatitis.

Methods: This cross-sectional study was performed on 56 children (29 males and 27 females) with atopic dermatitis who were referred to the Dezyani Asthma and Allergy Clinic in Gorgan between 2016 and 2017. Atopic dermatitis was confirmed via the Prick test. Data were analyzed using SPSS 16 at a significant level of 0.05 .

Results: Average age of the subjects was $4.26 \pm 3.79$ years. The most common inhalant allergens were mite $(35.7 \%)$ and salt grass $(3.6 \%)$ and the most common food allergens were egg white (35.7\%) and cow's milk (26.8\%).

Conclusion: Considering the high prevalence of food allergy in the studied population, it is necessary to reduce the severity of allergic reactions and its subsequent treatment costs by observing the principles of a healthy diet and lifestyle.

KEYWORDS: Atopic dermatitis; Inhalant allergen; Food allergen; Prick test

\section{$\begin{array}{lll}\text { Received: 2019/03/03 } & \text { Revised: 2019/03/15 } & \text { Published:2019/04/29 }\end{array}$}

*Correspondence: Dr Mohsen Ebraimi,

Address: Neonatal and Children's Health Research Center, Golestan University of Medical Sciences, Gorgan, Iran

Telephone: +98-9113765214 Email: dr.ebrahimi2019@gmail.com 


\section{INTRODUCTION}

Atopic dermatitis or eczema is an inflammatory skin disorder characterized by severe itching, erythema, edema and flaking (1). The disease mostly appears in childhood and is recognized as the most common inflammatory skin disease in this period. People with a positive family history and other atopic disorders including asthma, allergic rhinitis and food allergy are more likely to develop the disease (2-4). The prevalence of atopic dermatitis in industrialized countries has increased over the past three decades. According to epidemiological studies, the disease affects 2$10 \%$ of adults and $5-30 \%$ of children $(2,4,5)$. Genetic and environmental factors influence the incidence of atopic dermatitis. Children living in urban areas are more likely to develop allergic diseases. Exposure to pollutants and allergens in closed environments and reduced breastfeeding rates may be associated with the increased prevalence of this disease. Improving the health status of children and raising awareness about atopic dermatitis can be beneficial for controlling this disease (4).

Food allergy refers to an abnormal immune response to a certain food, regardless of the physiological effects of that type of food. Eggs, milk, peanut, wheat and soybean are among common food allergens. Food allergy in patients with atopic dermatitis is of clinical importance since it may interfere with the treatment process of the patients. Food allergy is observed in almost 30\% of patients with atopic dermatitis, most of whom are children younger than 3 years of age. In the United States, about $6 \%$ of children and $3.7 \%$ of adults have food allergy. Food allergies are not diagnosed at the right time due to lack of specific symptoms (4).

Inhalant allergens such as house dust mite (HDM), grass, ragweed pollen, molds and animal- and bacteria-related allergens are responsible for skin and respiratory allergies in children and adults $(6,7)$. Various studies in Iran have investigated the prevalence of food and inhalant allergens in people with atopic dermatitis (1, 4, 8-11). Recent studies
Have emphasized on the role of environmental factors such as air temperature, humidity, pollution and radiation intensity (12-15). Considering the environmental characteristics of Northern provinces of Iran, we aimed to determine the prevalence of sensitization to food and inhalant allergens in patients with atopic dermatitis in the Golestan Province, north of Iran.

\section{MATERIALS AND METHODS}

This cross-sectional study was conducted on patients with atopic dermatitis who were referred to the Dezyani Asthma and Allergy Clinic in Gorgan (Golestan Province, Iran) during 2016-17. Patients over 4 months of age who had not received anti-histamines and corticosteroids in the two weeks prior to the prick test, as well as those without dermatographism were included in the study. Individuals with a history of septic shock or heart attack, pregnant women and women with hereditary angioedema were excluded from the study.

Atopic dermatitis was diagnosed using the prick test in which histamine and physiological saline were used as the positive and negative controls, respectively. A raised bump (more than $3 \mathrm{~mm}$ ) surrounded by a small circle of itchy red skin indicated a positive reaction. The test was done for 15 food allergens and 10 inhalant allergens. The allergen selection criterion was based on the availability of the extracts and high prevalence of allergens. Based on the comments of a pulmonologist and a clinical immunologist, and severity of asthma, the subjects were divided into three groups: mild asthma, moderate asthma and severe asthma. Written consent was taken from parents of the subjects. Necessary information was extracted from the patients' medical records. Data were presented using descriptive statistics, such as mean, standard deviation (SD) and frequency. Comparison of sensitization to allergens between the groups was done using the Chisquare test and Fisher's exact test. This comparison was made for allergens with a prevalence of greater than four. All statistical 
analyses were performed in SPSS 16 at a significance level of 0.05 .

\section{RESULTS}

Overall, 56 subjects (29 males and 27 females) with an average age of $4.26 \pm 3.79$ years were diagnosed with atopic dermatitis according to the prick test. Thirty-three $(58.9 \%)$ subjects were living in urban areas and 23 subjects $(41.1 \%)$ were living in rural areas. Moreover, 20 subjects $(35.7 \%)$ had a history of allergic disease, of whom eight
(40\%) had asthma, six (30\%) had food allergy, three $(15 \%)$ had allergic rhinitis and three $(15 \%)$ had hives.

Based on the severity of asthma, atopic dermatitis was classified as mild, moderate and severe in $41.1 \%, 53.6 \%$ and $5.4 \%$ of the subjects, respectively. The most common symptoms were dry skin (96.4\%), erythema $(58.9 \%)$, itching $(51.8 \%)$, growth retardation $(5.4 \%)$ and restlessness (3.6\%) (Figure 1).

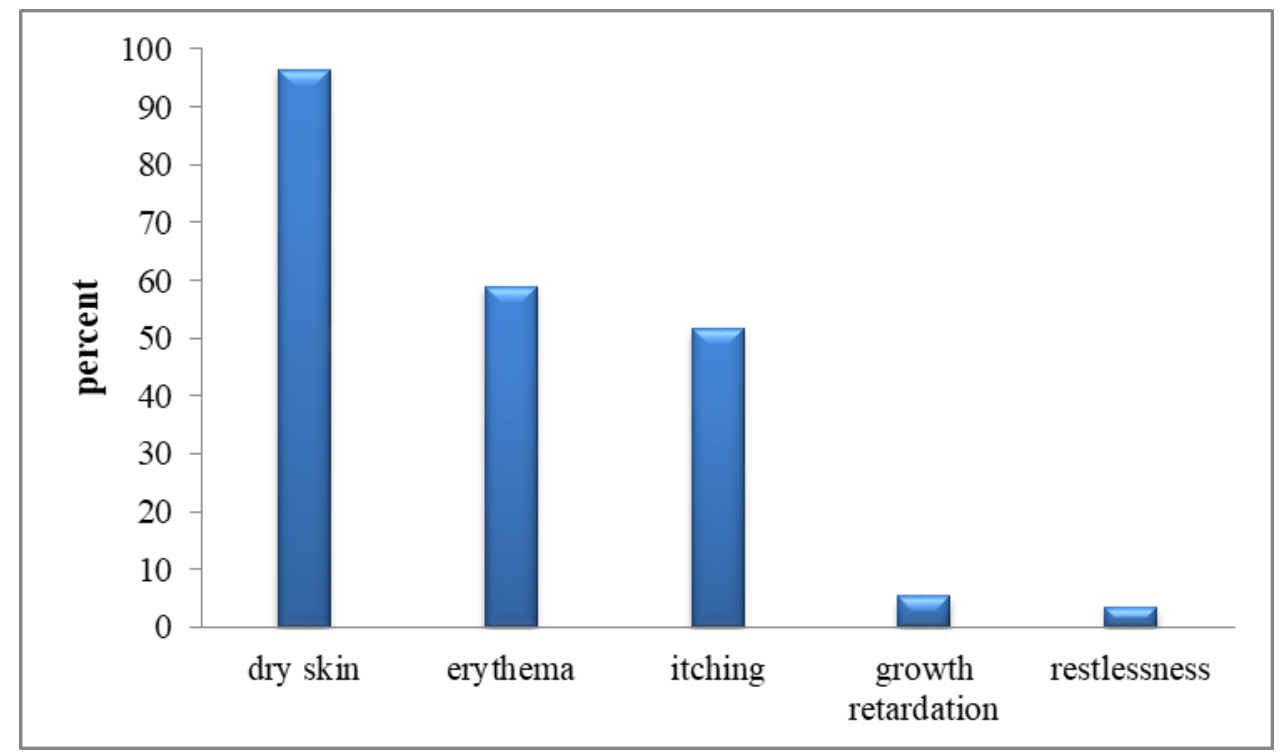

Figure 1. Distribution of clinical signs in patient with atopic dermatitis in Gorgan

Mite was the most common $(35.7 \%)$ inhalant allergen, followed by weed (salt grass), beetles and dogs (Figure 2).

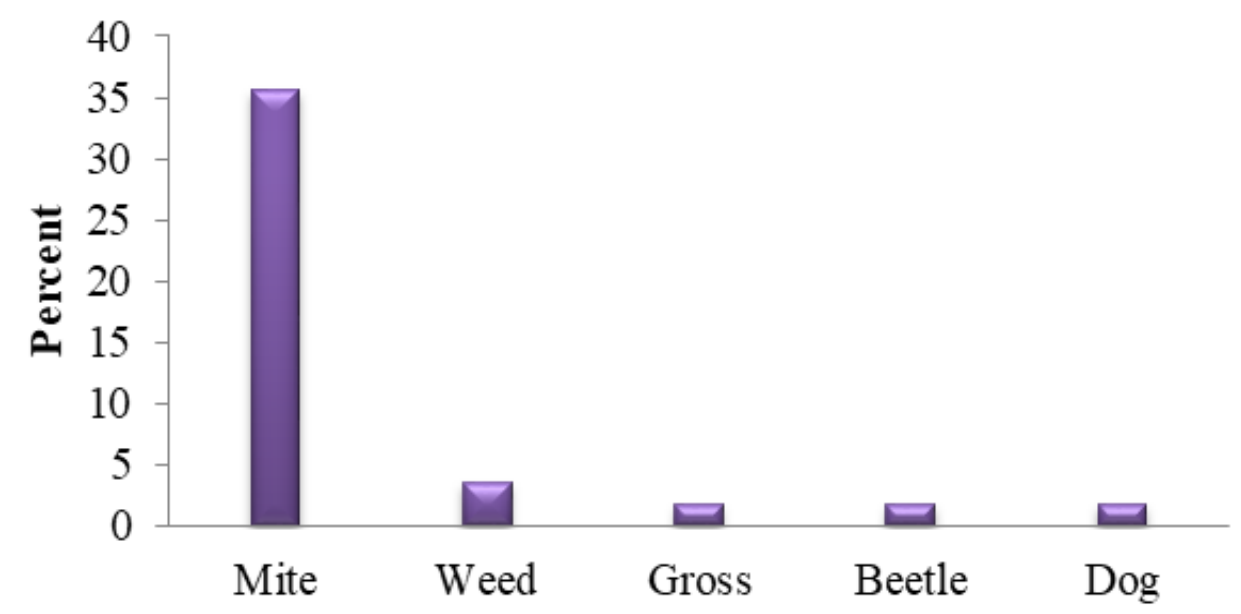

Figure 2. Distribution of sensitization to inhalant allergens in patients with atopic dermatitis in Gorgan 
The most common food allergens were egg white $(35.7 \%)$, cow's milk $(26.8 \%)$ and wheat $(14.3 \%)$. Other food allergens were peanut butter, soybean, fish, walnut, beef, egg yolk,

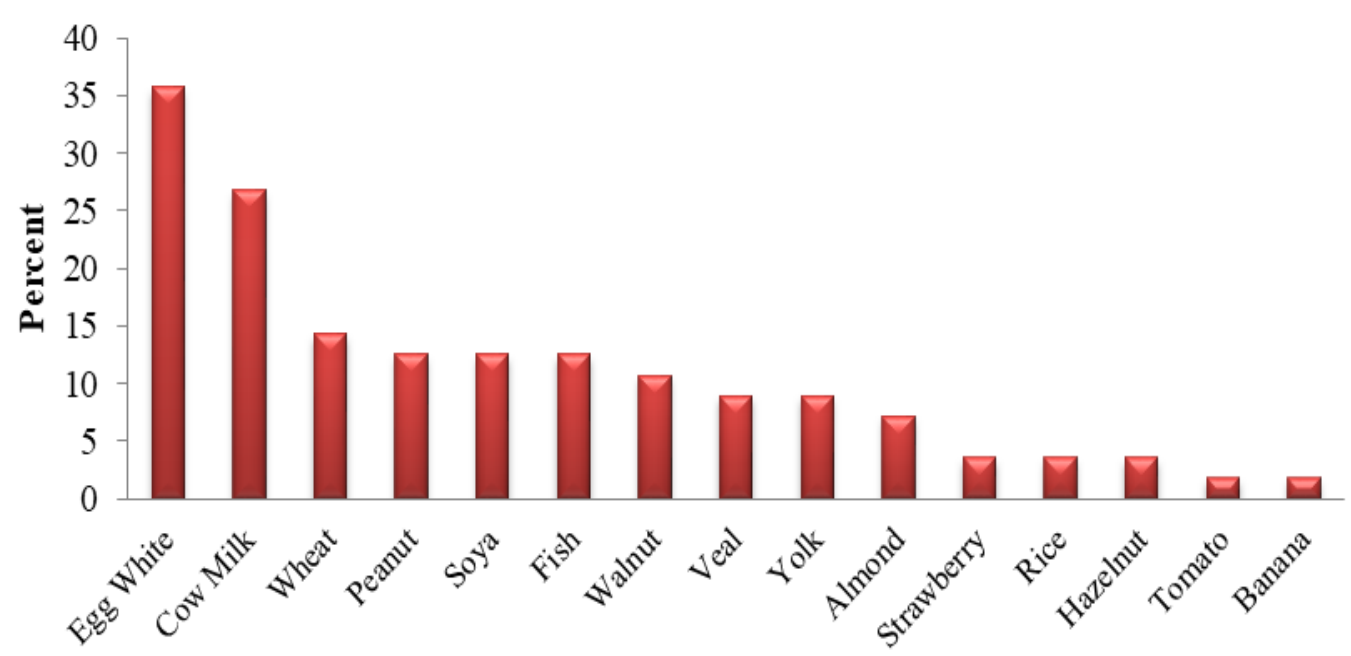

almond, strawberry, rice, hazelnut, tomato, banana and pistachio (Figure 3). Food allergies were about 3.5 times more prevalent that respiratory allergies.

Figure 3. Distribution of sensitization to food allergens in patients with atopic dermatitis in Gorgan

When studying the association of allergies with age, we found that allergic reaction to mite was significantly more prevalence in children older than 3 years. Among food allergens, allergic reaction to egg white and

Table 1. Frequency of food and inhalant allergens in patients with atopic dermatitis based on age, cow's milk was significantly more prevalent in children aged $\leq 3$ years, while allergy to almond was significantly more common in children older than 3 years (Table 1).

\section{gender and place of residence}

\begin{tabular}{|c|c|c|c|c|c|c|c|c|c|c|}
\hline & \multicolumn{3}{|c|}{ Gender } & \multicolumn{3}{|c|}{ Age } & \multicolumn{3}{|c|}{ Place of residence } \\
\hline & & Male & Female & $\begin{array}{c}\text { P- } \\
\text { value }\end{array}$ & $\geq 3$ & $<3$ & $\begin{array}{c}\text { P- } \\
\text { value }\end{array}$ & Urban & Rural & $\begin{array}{c}\text { P- } \\
\text { value }\end{array}$ \\
\hline \multirow{15}{*}{ 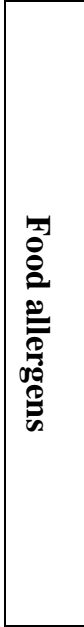 } & Egg white & $10(34 \%)$ & $10(37 \%)$ & 0.89 & $15(57 \%)$ & $5(16 \%)$ & $0.002 *$ & $11(37 \%)$ & $9(39 \%)$ & 0.78 \\
\hline & Cow's milk & $7(24 \%)$ & $8(29 \%)$ & 0.76 & $13(50 \%)$ & $2(6.6 \%)$ & $0.001^{*}$ & $9(27 \%)$ & $6(26 \%)$ & 1 \\
\hline & Wheat & $3(10 \%)$ & $5(18 \%)$ & 0.46 & $6(23 \%)$ & $2(6.6 \%)$ & 0.12 & $4(12 \%)$ & $4(17 \%)$ & 0.7 \\
\hline & Peanut & $6(20 \%)$ & $1(3.7 \%)$ & 0.1 & $3(11 \%)$ & $4(13 \%)$ & 1 & $5(15 \%)$ & $2(8.6 \%)$ & 0.68 \\
\hline & Almond & $3(10 \%)$ & $1(3.7 \%)$ & 0.61 & 0 & $4(13 \%)$ & 0.11 & $2(6 \%)$ & $2(8.6 \%)$ & 1 \\
\hline & Soya & $2(6.8 \%)$ & $2(7.4 \%)$ & 1 & $3(11 \%)$ & $1(3 \%)$ & 0.32 & $3(9 \%)$ & $1(4.3 \%)$ & 0.63 \\
\hline & Fish & $4(13 \%)$ & $3(11 \%)$ & 1 & $5(14 \%)$ & $3(10 \%)$ & 0.69 & $5(15 \%)$ & $2(8.6 \%)$ & 0.68 \\
\hline & Walnut & $4(13 \%)$ & $1(3.7 \%)$ & 0.67 & $3(11 \%)$ & $3(10 \%)$ & 1 & $3(9 \%)$ & $3(13 \%)$ & 0.68 \\
\hline & Yolk & $3(10 \%)$ & $2(7.4 \%)$ & 1 & $2(7.6 \%)$ & $3(10 \%)$ & 0.417 & $4(12 \%)$ & $1(4.3 \%)$ & 0.63 \\
\hline & Veal & $2(6.8 \%)$ & $3(11 \%)$ & 0.66 & $5(14 \%)$ & $1(3.3 \%)$ & 0.17 & $2(6 \%)$ & $3(13 \%)$ & 0.39 \\
\hline & Strawberry & $2(6.8 \%)$ & 0 & 0.49 & 0 & $2(6.6 \%)$ & 0.49 & 0 & $2(8.6 \%)$ & 0.16 \\
\hline & Rice & $1(3.4 \%)$ & $1(3.7 \%)$ & 1 & $2(7.6 \%)$ & 0 & 0.21 & $2(6 \%)$ & 0 & 0.5 \\
\hline & Hazelnut & $0(0 \%)$ & $3(11 \%)$ & 0.22 & $1(3.8 \%)$ & $1(3.3 \%)$ & 1 & $1(3 \%)$ & $1(4.3 \%)$ & 1 \\
\hline & Banana & $1(3.4 \%)$ & 0 & 1 & 0 & $1(3 \%)$ & 1 & $1(3 \%)$ & 0 & 1 \\
\hline & Pistachios & $1(3.4 \%)$ & 0 & 1 & $1(3.8 \%)$ & 0 & 1 & $1(3 \%)$ & 0 & 1 \\
\hline \multirow{4}{*}{ 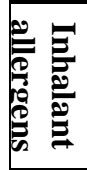 } & Mite & $11(37 \%)$ & $9(33 \%)$ & 0.78 & $5(14 \%)$ & $13(43 \%)$ & $0.04 *$ & $14(42 \%)$ & $6(26 \%)$ & 0.26 \\
\hline & Beetle & $1(3.4 \%)$ & 0 & 1 & 0 & $1(3.3 \%)$ & 1 & $1(3 \%)$ & 0 & 1 \\
\hline & Weed & $1(3.4 \%)$ & $1(3.7 \%)$ & 1 & 0 & $2(6.6 \%)$ & 1 & $1(3 \%)$ & $1(4.3 \%)$ & 1 \\
\hline & Grass & $1(3.4 \%)$ & 0 & 1 & 0 & $1(3.3 \%)$ & 1 & 0 & $1(4.3 \%)$ & 0.41 \\
\hline
\end{tabular}

*Significant difference between the groups 


\section{DISCUSSION}

In this cross-sectional study, we evaluated the prevalence of allergic reactions to different food and inhalant allergens in patients with atopic dermatitis. Various studies have provided evidence of an association between the incidence of atopic dermatitis and allergies. For example, a study in Japan reported a significant relationship between atopic dermatitis and incidence of allergic rhinitis, bronchial asthma and food allergy, so that the age of onset of these conditions was significantly lower in those with atopic dermatitis (16). In a study by Onsori et al., $30 \%$ of patients with atopic dermatitis had food allergy, asthma, allergic rhinitis and hives (8). In our study, $35.7 \%$ of subjects with atopic dermatitis had asthma, food allergy, allergic rhinitis and hives. However, some studies have reported even higher prevalence rates for allergies among patients with atopic dermatitis. For instance, in a study by Fouladseresht, $59.2 \%$ of patients with atopic dermatitis reacted to at least one allergen (10). Röckman et al. reported the prevalence of food allergies to be $74.4 \%$ in patients with atopic dermatitis, of which $20.4 \%$ were asymptomatic (20). However, it has to be mentioned that this study has been carried out on adults, whilst our study subjects were children.

In a previous study in Iran, prevalence of respiratory and food allergies was $55.9 \%$ and $21.7 \%$, respectively (10). However, in our study, the prevalence of respiratory and food allergies was $39.2 \%$ and $35.7 \%$, respectively. Egg yolk, egg white, peanut, walnut, soybean, cow's milk and curry powder have been reported as the most common food allergens $(2,4)$. In the present study, reaction to egg white and cow's milk was more common than other allergens. Similar to our findings, previous studies have reported HDM, salt grass, Alternaria spores, pigweed and spinach as the most common inhalants allergens $(1,9$, $10)$.

In the present study, there was no correlation between incidence of food allergies and gender in patients with atopic dermatitis, which is in line with findings of Onsori et al.
(8). However, in the study of Fouladseresht, the prevalence of allergies to beetle, egg yolk, egg white and tomato differed significantly between men and women (10).

According to Ahanchian et al., food allergies are more prevalent in younger individuals, while the prevalence of respiratory allergies is higher in older individuals (1), which is in line with our findings.

In a study in Poland, the prevalence of atopic dermatitis differed significantly between adults living in rural and urban areas, but no difference was found among children with atopic dermatitis (5). We also found no significant correlation between place of residence and incidence of atopic dermatitis in children.

The difference between results of the previous studies and our study could be attributed to climate and environmental factors (12-15). Given the importance of environmental factors on the incidence of atopic dermatitis, it is suggested to conduct studies on food and inhalant allergens in several provinces.

\section{CONCLUSION}

Considering the high prevalence of food allergy in the studied population, it is necessary to reduce the severity of allergic reactions and its subsequent treatment costs by observing the principles of a healthy diet and lifestyle.

\section{DECLARATIONS}

\section{Funding}

This study was supported by a grant from "Neonatal \& Children's Health Research Center" of the Golestan University of Medical Sciences, Iran.

\section{Ethics approvals and consent to participate}

Written consent was obtained from all participants. The study received approval from the Ethics Committee of Golestan University of Medical Sciences (ethics code: IR.goums.REC.1396.238).

\section{Conflict of interest}


The authors declare that there is no conflict of interest regarding the publication of this article.

\section{REFERENCES}

1. Ahanchian H, Jafari SA, Jabbari F, Kianifar HR, Karimi N, Khakshur A, Kiani MA. Evaluation of common allergens in children with atopic dermatitis by skin prick test. Journal of North Khorasan University of Medical Sciences. 2013; 5(3):551-5 [In persian]. [DOI:10.29252/jnkums.5.3.551]

2. Röckmann $\mathrm{H}$, van Geel MJ, Knulst AC, Huiskes J, Bruijnzeel-Koomen CA, de BruinWeller MS. Food allergen sensitization pattern in adults in relation to severity of atopic dermatitis. Clinical and translational allergy. 2014;4(1):9. [DOI:10.1186/2045-7022-4-9]

3. Wisniewski J, Agrawal R, Minnicozzi S, Xin W, Patrie J, Heymann P, et al. Sensitization to food and inhalant allergens in relation to age and wheeze among children with atopic dermatitis: Clinical Mechanisms in Allergic Disease. Clinical \& Experimental Allergy. 2013; 43(10):1160-70. [DOI:10.1111/cea.12169]

4. Salehi T, Pourpak Z, Karkon S, Shoormasti RS, Sabzevari SK, Movahedi M, Gharagozlou M, Moin M. The study of egg allergy in children with atopic dermatitis. World Allergy Organization Journal. 2009;2(7):123. [DOI:10.1097/WOX.0b013e3181abe7cb]

5. Kupryś-Lipińska I, Elgalal A, Kuna P. The epidemiology of atopic dermatitis in the general population of the Lodz province's citizens. Advances in Respiratory Medicine. 2009;77(2):145-51.

6. Robert M. Kliegman M, Bonita M.D. Stanton, MD, Joseph St. Geme, MD and Nina F Schor, $\mathrm{MD}, \mathrm{PhD}$. Nelson Textbook of Pediatrics. 20 ed2016. p. 1121.

7. Stajminger G, Marinović-Kulisić S, Lipozencić J, Pastar Z. Most common inhalant allergens in atopic dermatitis, atopic dermatitis/allergic rhinitis, and atopic dermatitis/bronchial asthma patients: a five-year retrospective study. Acta dermatovenerologica Croatica: ADC. 2007;15(3):130-4.
8. Onsori F, Ahmadi A, Mansori M, Mosavi Khorshidi SM, Pazoki N, Salimian J. Prevalence of food allergens in patients with atopic dermatitis referring to the asthma and allergy clinic in Tehran in 2014. J Scientific Journal of Kurdistan University of Medical Sciences. 2016;21(1):40-6 [In Persian].

9. Farrokhi S, Gheybi MK, Movahed A, Iranpour D, Ostovar A, Vahdat K, Khazaei HA. Evaluation of the frequency of food and aeroallergens in patients with eczema and urticaria in province of Bushehr: based on skin prick test reactivity. ISMJ. 2014; 17(4):629-37 [In Persian].

10. Fouladseresht H. Prevalence of food and airborne allergens in allergic patients in Kerman. Journal of kermanshah university of medical sciences (behbood). 2014; 18(4):234-41 [in persian].

11. Ghaderi R, Tabiee S, Peyrovi S, Jafari Pour M. Prevalence of atopic dermatitis and its risk factors in 2-5 years old children at kindergartens of Birjand city (2008). JOURNAL OF KERMANSHAH UNIVERSITY OF MEDICAL SCIENCES (BEHBOOD). 2012;19(3):286-93 [In Persian].

12. Kantor R, Silverberg JI. Environmental risk factors and their role in the management of atopic dermatitis. Expert review of clinical immunology. 2017;13(1):15-26.

[DOI:10.1080/1744666X.2016.1212660]

13. Li A, Fan L, Xie L, Ren Y, Li L. Associations between air pollution, climate factors and outpatient visits for eczema in West China Hospital, Chengdu, south-western China: a time series analysis. Journal of the European Academy of Dermatology and Venereology. 2018;32(3):486-94. [DOI:10.1111/jdv.14730]

14. Nguyen GH, Andersen LK, Davis MD. Climate change and atopic dermatitis: is there a link?. International journal of dermatology. 2019;58(3):279-82 [DOI:10.1111/ijd.14016]

15. Guo Q, Liang F, Tian L, Schikowski T, Liu $\mathrm{W}$, Pan X. Ambient air pollution and the hospital outpatient visits for eczema and dermatitis in Beijing: a time-stratified case-crossover analysis. Environmental Science: Processes \& Impacts. 2019;21(1):163-73. [DOI:10.1039/C8EM00494C] 
16. Kijima A, Murota H, Takahashi A, Arase N, Yang L, Nishioka M, et al. Prevalence and impact of past history of food allergy in atopic dermatitis. Allergology International. 2013;62(1):105-12. [DOI:10.2332/allergolint.12-OA-0468] 